\title{
Avaliação em emergia como ferramenta de gestão nos parques urbanos de São Paulo
}

\section{Evaluation of the production and management of ecosystem services in urban parks of São Paulo}

\author{
Mirtes Vitoria Mariano' \\ Cecilia Maria Villas Bôas de Almeida ${ }^{1}$ \\ Silvia Helena Bonilla \\ Feni Agostinho' \\ Biagio Fernando Giannetti ${ }^{1}$
}

\begin{abstract}
Resumo: O município de São Paulo vem investindo na implantação de áreas verdes para melhoria da qualidade de vida da população. Neste sentido, a Secretaria do Verde e do Meio Ambiente do município de São Paulo vem ampliando a cobertura vegetal por meio de um programa de arborização e da criação de novos parques urbanos. Entretanto, não há uma avaliação quantitativa dos benefícios ambientais providos por esta iniciativa. Este trabalho utiliza a contabilidade ambiental em emergia para avaliar 73 parques da cidade de São Paulo. Para todo o conjunto dos parques, foram calculados os indicadores e os custos em emergia a fim de avaliar quais parques aproveitam mais os recursos da natureza, quais demandam maiores investimentos da prefeitura e quais fornecem maior quantidade de serviços ambientais para a cidade. A razão entre os recursos da natureza e os recursos provenientes da economia (I/F) foi estabelecida como um importante indicador para a gestão dos parques urbanos existentes e a relação $\mathrm{I} / \mathrm{F} \times \mathrm{Em} \$ / \mathrm{m}^{2}$ é proposta como indicador para tomada de decisão, permitindo determinar a melhor configuração de cada parque e priorizar as ações para novos projetos e para a manutenção dos antigos.
\end{abstract}

Palavras-chave: Gestão; Serviços ambientais; Produção de serviços ambientais; Parques urbanos.

\begin{abstract}
The municipality São Paulo has been investing in the deployment of green areas for improving citizens' quality of life. In this regard, the "Secretaria do Verde e do Meio Ambiente" of São Paulo has been increasing green areas through an afforestation program and the creation of new urban parks. By means of emergy environmental accounting, this paper evaluates 73 parks in São Paulo. However, there is no quantitative assessment regarding the environmental benefits of this initiative. Emergy indices and costs have been accounted to assess whether parks properly utilize natural resources; which parks use the local environmental resources properly; which ones demand more investment by the municipality; and which ones generate greater profit to the city's prefecture in terms of environmental services. The ratio between natural resources and those from the economy $(I / F)$ was established as an important indicator to assist the management of the existing urban parks. The relationship $I / F \times E m \$ / m^{2}$ is proposed as a tool for decision-making, determining the best configuration of each park and prioritizing actions for new projects and the maintenance of the old ones.
\end{abstract}

Keywords: Emergy; Environmental indicators; Environmental accounting; Urban parks.

\section{Introdução}

O município de São Paulo possui uma extensão territorial de 1.523 quilômetros quadrados (IBGE, 2011) com uma população de aproximadamente onze milhões de habitantes (IBGE, 2011). Uma população com esta dimensão exige grandes áreas destinadas a moradias, recursos da agricultura e pecuária e recursos para o desenvolvimento de novas tecnologias. Com o crescimento da cidade e o adensamento da população, o solo com cobertura impermeável substitui as áreas verdes, causando um efeito desfavorável no bem-estar da população e do ambiente (Brabec et al., 2002; Meyer \& Turner, 1994).

Estudos desenvolvidos pela Prefeitura Municipal de São Paulo (Kliass, 1993; Silva, 1993) mostraram que, no início da década de 1990, apenas 16,36\% do município eram ocupados por áreas verdes, sendo

\footnotetext{
${ }^{1}$ Programa de Pós-graduação em Engenharia de Produção, Universidade Paulista - UNIP, Rua Dr. Bacelar, 1212, Vila Clementino, CEP 04026-002, São Paulo, SP, Brasil, e-mail: mirtesmariano@uol.com.br; cmvbag@unip.br; bonilla@unip.br; feniagostinho@gmail.com; biafgian@unip.br
} 
$10,24 \%$ na zona urbana e $6,12 \%$ na zona rural. Estes estudos já evidenciavam um problema que se agravou com o passar dos anos: a falta de áreas verdes com consequente influência negativa na qualidade de vida da população.

A noção de "parque" esteve, por muito tempo, associada a serviços de estética e recreação. Como as condições e necessidades da cidade mudaram, a ideia de recreação passou a incluir a disponibilização de atividades esportivas para todas as classes sociais, com a implantação de quadras poliesportivas, pistas de Cooper e equipamentos de ginástica nas áreas verdes públicas. Entretanto, Kliass (1993), ao definir parque urbano, reforçava a função de lazer reafirmando que os parques urbanos deveriam atender às demandas de equipamentos para as atividades de recreação, mas eram, ao mesmo tempo, espaços amenizadores das estruturas urbanas, compensadores das massas edificadas.

As áreas urbanas arborizadas prestam inúmeros serviços sociais, ambientais e econômicos para as cidades (Escobedo et al., 2008; Conway \& Urbani, 2007; Mcpherson et al., 2005). Vários autores (Chen \& Jim, 2008; McPherson \& Simpson, 2002; Nowak \& Dwyer, 2000) relacionam as áreas urbanas arborizadas com a estética, a redução de ruído e a manutenção de habitat para animais silvestres. A sombra das árvores diminui o aquecimento de superfícies construídas e pavimentadas e, por meio da evapotranspiração, pode, também, reduzir os efeitos das ilhas de calor que são intensificadas com o crescimento da cidade (Akbari et al., 2001; Rosenfeld et al., 1995). Xiao \& McPherson (2002) e Xiao et al. (1998) enfatizam o benefício proporcionado pelos parques urbanos pela diminuição do volume de escoamento de água da chuva com consequente redução dos riscos de inundações. Neste contexto, a preocupação com a preservação e implantação de parques municipais está associada não apenas ao lazer e à estética, mas principalmente aos serviços ambientais que estes podem prestar a uma determinada área.

Reconhecendo o papel dos parques públicos como fornecedores de lazer, cultura e serviços ambientais, a Prefeitura Municipal de São Paulo, por meio da Secretaria do Verde e do Meio Ambiente, lançou em 2008 o programa "100 parques". Este programa previa a instalação de parques públicos no município com o objetivo de "[...] proteger a biodiversidade e ampliar as opções de lazer da população [...]" (SVMA, 2010). O programa incluía, também, a implantação de parques lineares para prevenir as construções indevidas em áreas de risco e operar como drenos de água minimizando enchentes. Estes parques implantados e mantidos pela prefeitura de São Paulo são hoje considerados estruturas produtoras de serviços ambientais, lazer, educação e cultura. Porém, a existência e manutenção destas estruturas dependem da disponibilidade de fluxos de um fluxo constante de energia, quer na forma de recursos naturais, como também na forma de recursos da economia como mão de obra e energia fóssil (Huang et al., 2009).

O presente trabalho tem por objetivo quantificar o investimento da sociedade e da natureza na operação e avaliar os serviços ambientais produzidos por um conjunto de 73 parques municipais de São Paulo. Para tanto, se emprega e se propõe a contabilidade em emergia como ferramenta de avaliação e tomada de decisão no gerenciamento dos parques existentes e no projeto de novos parques. De forma mais específica, este trabalho propõe responder às seguintes perguntas:

- Qual a relação área verde/área construída mais favorável para fornecer o conjunto de produtos (serviços ambientais, lazer e qualidade de vida) de um parque urbano?

- Qual a relação custo benefício no que tange à produção de serviços ambientais?

\section{Revisão bibliográfica}

\subsection{Contabilidade em emergia}

A emergia é a energia disponível de um determinado tipo, previamente requerida, direta ou indiretamente, para obter um bem ou um serviço (Odum, 1996). As diferentes contribuições de energia para gerar um produto ou serviço são expressas em uma base comum (em joules de energia solar, seJ) permitindo sua contabilidade. O desempenho do sistema e a sua interação com o meio ambiente é avaliado com a contabilização dos fluxos renováveis $(\mathrm{R})$, não renováveis $(\mathrm{N})$ e provenientes da economia $(\mathrm{F})$ empregados para sua implantação e operação.

\subsection{Estudos sobre o papel dos parques urbanos}

É consenso entre todos ou autores que a composição do verde urbano desempenha importante papel na manutenção da qualidade ambiental das cidades e, portanto, da qualidade de vida dos cidadãos. Dentre os benefícios decorrentes da sua implantação adequada, os mais citados são:

- estabilização microclimática e redução das ilhas de calor;

- redução da poluição atmosférica, por meio da retenção de dióxido de carbono;

- redução da poluição sonora;

- aprimoramento da paisagem urbana;

- contribuição para a qualidade de vida da população, por meio da aproximação com o meio natural. 
E apenas quando se trata de parques lineares se menciona a contribuição para o controle de enchentes e inundações.

Com relação ao investimento econômico para a implantação e manutenção de parques urbanos, Millward \& Sabir (2011) investigaram o valor dos serviços prestados pelas árvores em Allan Gardens e mostraram que o dinheiro gasto para o plantio e manutenção de árvores era justificado pelos benefícios para o entorno da cidade. McPherson et al. (2005), avaliaram esses benefícios e concluíram que, a cada dólar investido na manutenção e implantação de áreas verdes urbanas, os benefícios retornam aproximadamente entre US\$1,37 e US\$3,09 ao ano.

Neste contexto, muitos artigos tratam dos benefícios das áreas verdes na qualidade de vida da população. Bolund \& Hunhammar (1999) avaliaram os serviços gerados por sete diferentes ecossistemas (árvores de rua; parques gramados, florestas urbanas; terra cultivada; zonas úmidas; lagos e rios urbanos) e identificaram serviços relevantes como: filtragem de ar, regulação do microclima, redução de ruído, drenagem de águas pluviais, valores culturais e recreativos. Com o objetivo de apresentar os efeitos climáticos relacionados com a vegetação no meio urbano em confronto com a presença de construções, Dimoudi \& Nikolopoulou (2003) calcularam a transmissão de calor com base no albedo e na permeabilidade do solo. Os resultados mostraram que o aumento no tamanho da área verde urbana reduz efetivamente a temperatura do ar ambiente. Resultados similares foram obtidos por Lin et al. (2011), utilizando a ferramenta Landsat Enhancet Thematic Mapper Plus identificaram diferenças de temperatura resultantes da presença de áreas verdes e suas áreas estendidas. Esses autores correlacionaram as áreas verdes com a economia de carbono devida ao resfriamento das vizinhanças, concluindo que: (1) quanto maior a quantidade de biomassa, maior o resfriamento, maior a economia de energia e menor poluição atmosférica; (2) a instalação de maior quantidade de pequenas áreas verdes é mais benéfica que a implantação de poucas unidades de grande extensão; e (3) áreas verdes de formas irregulares têm melhor desempenho do que formas regulares de mesmo tamanho. Por outro lado, Oliveira et al. (2011) analisaram o desempenho térmico de um pequeno espaço verde ( 0,24 ha) com medições de parâmetros meteorológicos (temperatura, umidade relativa do ar, velocidade do vento, solar e radiação infravermelha) e atribuíram uma pequena influência nas condições climáticas locais, particularmente à baixa velocidade do vento.

Com base nas medidas dos potenciais benefícios (diferenças de temperatura e nível de ruído, economia de energia para aquecimento ou resfriamento, qualidade do ar e da água), a maioria dos autores considera que a presença de áreas verdes contribui para atenuar os efeitos do adensamento urbano. Muitos autores, também, associam a economia de energia elétrica ou o preço do $\mathrm{CO}_{2}$ no mercado de créditos de carbono com um valor monetário dos serviços ambientais fornecidos pelas áreas verdes e, assim, avaliam o investimento de implantacão/manutenção das áreas verdes. Entretanto, nenhum destes estudos emprega metodologia capaz de avaliar o valor dos recursos naturais, tanto no que diz respeito ao uso destes recursos como ao valor de serviços ecossistêmicos obtidos.

Em um artigo com título provocativo (Shared wealth or nobody's land? The worth of natural capital and ecosystem services), Ulgiati et al. (2010) abordaram maneiras de medir o valor dos recursos naturais e dos serviços do ecossistema em que se baseiam as economias humanas. Para estabelecer uma relação racional entre as atividades humanas e os recursos da natureza, os autores estabelecem duas categorias. A primeira, não comercializável, e, portanto, sem valor ou dono, como o ar limpo e água da chuva; a segunda, facilmente delimitada e comercializada, terras, florestas e água potável. Esses autores afirmam que o uso da contabilidade ambiental em emergia fornece uma base forte para a análise do valor do capital natural.

$\mathrm{Na}$ avaliação dos serviços ambientais empregando a contabilidade ambiental em emergia, os primeiros trabalhos avaliaram grandes áreas, que incluíam recursos naturais e atividades humanas (Higgins, 2003) e reservas naturais (Qin et al., 2000, Tilley \& Swank, 2003).

Higgins (2003) avaliou a região de Oak Openings no noroeste de Ohio, enfatizando a interação entre o meio ambiente, a economia e a cultura, e questionando a viabilidade dessa interação a longo prazo. Nesse trabalho, Higgins (2003) descreve três subsistemas operando concomitantemente: o ambiental, o econômico e o cultural. Cada um desses sistemas foi estudado empregando os indicadores de emergia e os resultados mostraram pouca habilidade do sistema em explorar recursos locais da natureza, moderado para alto estresse do ambiente e alto investimento em emergia. Qin et al. (2000) estudaram um mangue em Mai Po, a maior e mais importante zona úmida de Hong Kong. A avaliação, em emergia, integra o ecossistema e a economia do mangue e destaca como ponto forte do conjunto a educação (visitantes e pesquisa local). Tilley \& Swank (2003) empregaram a síntese de emergia para avaliar um projeto de gestão de uma floresta temperada em Southern Appalachian Mountains, nos EUA. Foi possível modelar a estrutura e a função de ecossistemas florestais, quantificá-las em unidades comuns e determinar um "sistema de valor" baseado na soma de recursos necessários para desenvolver e sustentar cada atividade. Segundo Tilley \& Swank (2003), para apreciar plenamente os benefícios sociais e econômicos das florestas, 
uma nova filosofia de gestão de ecossistemas deve considerar a importância de vários fatores, em várias escalas de espaço e tempo, e relacionar esses fatores com os serviços e produtos florestais.

A maioria dos estudos mais recentes que utilizam a contabilidade ambiental em emergia avaliam áreas no entorno de municípios. Alguns autores tratam da recuperação das áreas rurais (Su et al., 2012), outros, da recuperação e preservação de áreas verdes produtoras de serviços ambientais (Lu et al., 2005; Dang \& Liu, 2012) e apenas um avalia um parque urbano, o Green Lake Urban Wetland Park (Duan et al., 2011).

Com base em um projeto lançado pelo governo central chinês em 1999, Su et al. (2012) estudaram as interações entre os sistemas humanos e naturais na bacia Yanhe na China. Depois de dez anos de projeto, a bacia hidrográfica Yanhe passou por uma mudança bastante significativa no padrão de uso da terra caracterizada pela redução de terras e recuperação de vegetação (Zhao et al., 2006). Cinco serviços ecossistêmicos foram avaliados: produção primária líquida, sequestro de carbono/produção de oxigênio, conservação da água, conservação do solo e produção de grãos. Esses autores observaram que o aumento da produção primária líquida de biomassa contribui para a regulação/apoio e conservação de bacias hidrográficas. Entre os serviços dos ecossistemas, a variação da produção de grãos está negativamente correlacionada com a NPP e, consequentemente, com o sequestro de $\mathrm{CO}_{2}$ e a produção de $\mathrm{O}_{2}$. Partindo, também, de um programa de restauração ecológica na bacia de Yangou, Dang \& Liu (2012) utilizaram a síntese em emergia e a capacidade de suporte como medida de sustentabilidade. Nessa região, havia uma grande tensão entre crescimento econômico e a manutenção de processos ecológicos, com grande parte desta tensão decorrendo da falta de recursos financeiros da população. As melhorias decorrentes do programa foram relacionadas à diminuição no uso de recursos não renováveis, pela revegetação e conservação do solo; mas o estudo também sugere ações para a conservação dos recursos ambientais, para redução de fluxos de emergia para produção agrícola e para mudanças de estilo de vida dos habitantes locais. A restauração da vegetação foi, também, proposta por Lu et al. (2005) como a chave para a melhoria da produtividade regional. O modelo de restauração utilizou uma plantação de Acacia Mangium (espécie de árvore de rápido crescimento), um pomar de Citrus Reticulata (espécie de laranja), pastagens de Pennisetum Purpureum (espécie de capim para pastagens) e um viveiro de peixes. Com base no custo em emergia da plantação de Acacia Mangium e das pastagens, os autores associam uma elevada eficiência a estes dois subsistemas de restauração.
Um único trabalho utiliza a contabilidade ambiental em emergia para investigar um parque urbano, o Green Lake Urban Wetland Park, em Pequim (Duan et al., 2011). Foram avaliadas as entradas ambientais e de capital, os serviços ecossistêmicos e os rendimentos de matéria orgânica. A avaliação do ciclo de vida foi usada para estimar quantitativamente o impacto ambiental do parque, incluindo o potencial de aquecimento global, a eutrofização, o esgotamento de recursos não renováveis, o consumo de energia, a acidificação potencial, o potencial de criação fotoquímica de oxidante e a emissão de material particulado e resíduo. Os autores afirmam que com a combinação da contabilidade ambiental em emergia e da avaliação de ciclo de vida, mais informações podem ser obtidas sobre os fatores dominantes em cada fase do ciclo de vida e fornecer as oportunidades para reduzir impactos a fim de tornar o sistema mais sustentável.

Observou-se que os estudos que empregam a contabilidade ambiental em emergia para avaliar os benefícios dos serviços ecossistêmicos estão mais voltados a compreender e avaliar o funcionamento e a sustentabilidade de sistemas em que as atividades humanas interferem nos processos naturais (Qin et al., 2000; Higgins, 2003; Tilley \& Swank, 2003). Uma segunda vertente busca avaliar projetos de restauração de áreas rurais densamente populadas, em que se combina o uso de recursos naturais com as atividades rurais destinadas ao abastecimento de municípios (Lu et al., 2005; Dang \& Liu, 2012; Su et al., 2012). Os serviços ambientais destas áreas (produção de biomassa, evapotranspiração, sequestro de $\mathrm{CO}_{2}$ ) são avaliados com base na eficiência de produção ou por meio de indicadores (Duan et al., 2011). Entretanto, nenhum estudo utiliza a contabilidade ambiental em emergia para avaliar a relação custo/benefício no que tange ao uso destes recursos para a implantacão/ manutenção das áreas verdes e o valor de serviços ecossistêmicos obtidos, com exceção do trabalho de Giannetti et al. (2011). Esses autores avaliaram quatro serviços ambientais (infiltração da água no solo, produção primária líquida, evapotranspiração e a estrutura geológica do local) em uma fazenda de café no Cerrado Brasileiro, para verificar se os 80 hectares preservados de mata nativa, uma área de preservação maior do que as leis brasileiras exigem, seriam suficientes para compensar o impacto causado pela atividade agrícola. Com o auxílio de um diagrama ternário (Giannetti et al., 2006, Almeida et al., 2007), foi possível avaliar a contribuição da área natural preservada para a sustentabilidade do agronegócio. Com uma forte base científica, foram calculados os preços dos serviços ambientais e fornecidos subsídios para atribuir e/ou dividir a responsabilidade entre os usuários e os produtores de forma mais justa. 


\section{Metodologia}

\subsection{Coleta de dados}

Em julho de 2010, foi assinado um "Termo de Cooperação" entre a Prefeitura do Município de São Paulo por meio da Secretaria do Verde e Meio Ambiente (SVMA) e a Universidade Paulista (UNIP) com o objetivo de promover o desenvolvimento do projeto de pesquisa denominado "Avaliação dos Serviços Ambientais dos Parques no Município de São Paulo".

No ano de 2005, o município de São Paulo contava com 34 parques implantados. No final de 2008, este número subiu para 51 parques. Para realização deste trabalho, em 2010, a Secretaria do Verde e Meio ambiente forneceu os dados de 20 grupos, contabilizando 73 parques.

Para o levantamento de dados das fontes renováveis e não renováveis, foram utilizados sites da prefeitura do Município de São Paulo, da CRESESB (2011) (Centro de Referência para Energia Solar e Eólica de Sérgio de Salvo Brito), da CPTEC (Centro de Previsão de Tempo e Estudos Climáticos). O Google Earth (Google, 2012) foi utilizado para complementar as informações da SVMA quanto às áreas construídas, áreas cobertas com vegetação (nativa ou plantada) e áreas de gramado.

A Tabela 1 ilustra as emergias por unidade (UEV, Unit Emergy Value) utilizadas no trabalho, que foram coletadas na literatura (Odum, 1996).

\subsection{Indicadores de emergia}

Para a realização da contabilidade em emergia, utiliza-se um diagrama de energia, indicando os fluxos que compõem o sistema estudado, sejam eles fluxos de recursos naturais renováveis $(\mathrm{R})$, os recursos não renováveis $(\mathrm{N})$ e de recursos provenientes da economia (F). O diagrama apresenta também as interações do processo e suas saídas. A partir do diagrama de fluxos de energia, são feitas as tabelas contendo os recursos renováveis $(\mathrm{R})$, os recursos não renováveis $(\mathrm{N})$ e os provenientes da economia $(\mathrm{F})$ com seus respectivos valores em energia, emergia por unidade e a emergia. A UEV fornece uma medida da concentração de emergia e pode ser considerada como um indicador de qualidade por meio da razão entre emergia e energia, sendo que sua unidade é seJ/J (Odum, 1996). Quanto maior o valor da UEV, maior foi o trabalho para obter o produto e, portanto, maior a sua qualidade (Odum, 1996).

Foram empregados:

- o indicador de investimento em emergia $(\mathrm{EIR}=\mathrm{F} /(\mathrm{R}+\mathrm{N})=\mathrm{F} / \mathrm{I})$ que permite avaliar o investimento do município e da natureza para a existência/operação dos parques e a razão (I/F)
Tabela 1. Tabela de Emergia por unidade.

\begin{tabular}{lcc}
\hline \multicolumn{1}{c}{ Recursos } & Unidade & $\begin{array}{c}\text { Emergia por } \\
\text { unidade* } \\
\text { (seJ/unidade) }\end{array}$ \\
\hline Aço (equipamentos) & $\mathrm{kg}$ & $4,15 \times 10^{9}$ \\
Algodão & $\mathrm{kg}$ & $1,44 \times 10^{6}$ \\
Chuva (Geopotencial) & $\mathrm{J}$ & $4,70 \times 10^{4}$ \\
Chuva (Química) & $\mathrm{J}$ & $3,05 \times 10^{4}$ \\
Energia Geotérmica & $\mathrm{J}$ & $1,49 \times 10^{4}$ \\
Evapotranspiração & $\mathrm{J}$ & $2,69 \times 10^{4}$ \\
Grama & $\mathrm{J}$ & $4,26 \times 10^{3}$ \\
Infiltração da água no solo & $\mathrm{m}{ }^{3}$ & $6,85 \times 10^{11}$ \\
Irradiação solar & $\mathrm{J}$ & 1 \\
Mão de obra & $\mathrm{J}$ & $4,30 \times 10^{6}$ \\
Mata alta & $\mathrm{J}$ & $5,54 \times 10^{3}$ \\
Mudas (árvores) & $\mathrm{J}$ & $4,58 \times 10^{3}$ \\
Mudas (flores) & $\mathrm{J}$ & $4,17 \times 10^{3}$ \\
Mudas (grama) & $\mathrm{J}$ & $4,24 \times 10^{3}$ \\
Papel & $\mathrm{kg}$ & $2,38 \times 10^{9}$ \\
Plástico & $\mathrm{kg}$ & $5,76 \times 10^{9}$ \\
Produtos Químicos & $\mathrm{kg}$ & $6,38 \times 10^{8}$ \\
Solo Ocupado & $\mathrm{J}$ & $1,24 \times 10^{5}$ \\
Vento & $\mathrm{J}$ & $2,45 \times 10^{3}$ \\
\hline Base unitzata: & $\mathrm{m}$ & \\
\hline
\end{tabular}

*Base utilizada: $15,83 \times 10^{24} \mathrm{seJ} /$ ano (Odum et al., 2000).

foi empregada para avaliar a configuração dos parques (área natural/área construída).

- o indicador de rendimento em emergia $(\mathrm{EYR}=(\mathrm{R}+\mathrm{N}+\mathrm{F}) / \mathrm{F})$ utilizado para avaliar a contribuição em emergia dos parques urbanos para o município. Valores altos indicam que o retorno para o município é superior ao investido.

- $\mathrm{o}$ indicador de carga ambiental $(\mathrm{ELR}=(\mathrm{F}+\mathrm{N}) / \mathrm{R})$ que avalia a pressão que os fluxos requeridos para a existência/operação do parque exercem no meio ambiente.

- $\quad$ o índice de sustentabilidade (ESI = EYR/ELR) que avalia a maximização da contribuição do parque para o município e a minimização do estresse causado pelos fluxos requeridos para a implantação e operação dos parques.

- o Emdólar que se obtém dividindo-se o valor de emergia de cada fluxo pelo EMR e pode ser empregado para estimar o valor em emergia gasto no suporte da atividade humana (Odum, 1996). A relação entre emergia e moeda (EMR) é calculada dividindo-se a emergia do local dividido por seu PIB em determinado ano. Neste trabalho, utilizou-se o EMR do Estado de São Paulo 1,7x10 12 seJ/ano (Demétrio, 2011). 


\subsection{Serviços ambientais}

Foi observado que as áreas verdes dos parques urbanos da cidade de São Paulo são formadas principalmente por gramados, mata atlântica previamente existente e, em menor proporção, área de árvores plantadas. A variação, entre um parque e outro, está nas proporções de cada tipo de vegetação e na proporção de área construída.

A produção primária bruta corresponde ao total de matéria orgânica produzida em determinado tempo e área. A produção primária líquida (NPP) é a diferença entre a produção primária bruta e a quantidade de matéria orgânica consumida na respiração das plantas durante determinado período de tempo e área. $\mathrm{O}$ método detalhado para o cálculo da emergia desses serviços está mostrado no Anexo A.

\section{Resultados}

A Figura 1 ilustra o diagrama de fluxos para os parques municipais de São Paulo, em que se podem observar os fluxos renováveis (sol, chuva, vento e energia geotérmica), o fluxo não renovável (solo) e os fluxos provenientes da economia (mão de obra, equipamentos). Em cada parque, existem estoques de biomassa e espécies (animais e vegetais), um produtor de biomassa (área verde) e a infraestrutura construída (pistas de Cooper e caminhada, brinquedos, pistas de skate, aparelhos de ginástica, museus, etc.). Os produtos dos parques fornecidos para a cidade de São Paulo são os serviços ambientais, lazer e qualidade de vida.

Foram construídas 73 tabelas com a contabilidade em emergia dos parques em estudo no município. Como exemplo do modelo de cálculo para a construção das tabelas de contabilidade em emergia, utilizou-se o parque Siqueira Campos (Trianon, Tabela 2). Os resultados mostram que $20 \%$ da emergia total deste parque foi utilizada na implantação. Os recursos renováveis e os recursos provenientes da economia representam $18 \%$ e $62 \%$, respectivamente, do total dos recursos necessários para a operação do parque Trianon. A contribuição dos recursos não renováveis é menor que $1 \%$. A chuva química representa $16 \%$ do total de emergia no parque, sendo o recurso natural mais importante. Neste parque, com 12 funcionários, a mão de obra representa $62 \%$ da emergia total. Este percentual é maior que o da contribuição dos recursos renováveis (18\%), mostrando que o parque depende mais dos recursos fornecidos pelo município do que dos recursos naturais gratuitos.

\subsection{Razão entre os recursos da natureza (renováveis e não renováveis) e os recursos provenientes da economia (I/F)}

Os resultados obtidos mostram que a contribuição em emergia que um parque pode prover para o município depende da relação entre a contribuição do ambiente para a manutenção/operação do parque $(\mathrm{I}=\mathrm{N}+\mathrm{R})$ e $\mathrm{o}$ investimento do município em materiais e serviços (F). Desta forma, a razão I/F (razão entre $\mathrm{I}=\mathrm{N}+\mathrm{R} \mathrm{e} \mathrm{F}$ ) pode auxiliar na determinação da melhor estrutura a ser implantada de forma que o parque apresente baixos valores de EIR (investimento) e ELR (estresse) e altos valores de EYR (rendimento) e ESI (sustentabilidade).

Os resultados indicam que a manutenção da infraestrutura instalada para lazer e educação consome mais emergia do que a empregada para a produção de serviços ambientais. Vinte e seis por cento dos parques apresentam I/F menor que 0,1 . Dentre esses, alguns estão ainda em implantação como o Vila Silvia. Os restantes $36 \%$ dos parques apresentam $0,1<\mathrm{I} / \mathrm{F}<0,2$,

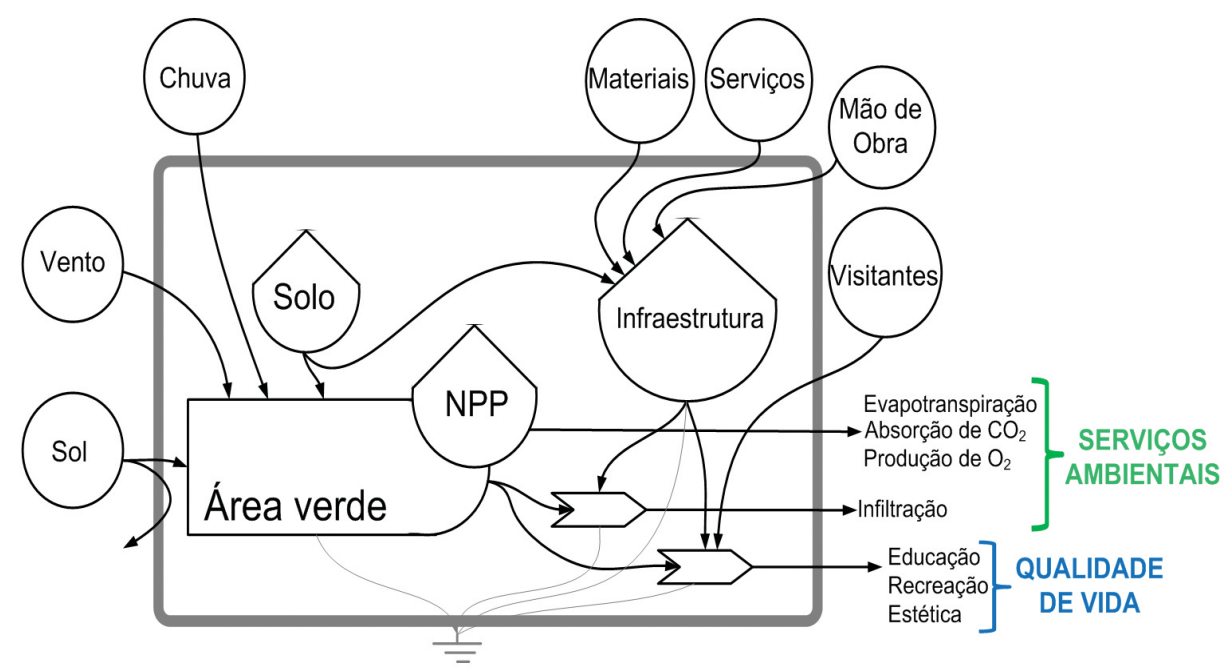

Figura 1. Diagrama de fluxos dos parques municipais de São Paulo. 
Tabela 2. Contabilidade em emergia do parque Trianon.

\begin{tabular}{|c|c|c|c|c|c|}
\hline \multicolumn{6}{|c|}{ Parque Trianon } \\
\hline & Unidade & $\begin{array}{c}\text { Energia } \\
\text { (unidade/ano) }\end{array}$ & $\begin{array}{c}\text { Emergia por } \\
\text { unidade } \\
\text { (seJ/unidade) }\end{array}$ & $\begin{array}{l}\text { Emergia } \\
\text { (seJ/ano) }\end{array}$ & $\begin{array}{c}\% \text { total de } \\
\text { emergia }\end{array}$ \\
\hline \multicolumn{6}{|c|}{ Implantação } \\
\hline \multicolumn{6}{|c|}{ Provenientes da Economia $(\mathrm{F})$} \\
\hline Aço & $\mathrm{g}$ & $3,09 \times 10^{5}$ & $2,77 \times 10^{9}$ & $8,56 \times 10^{14}$ & $1 \%$ \\
\hline Brita & $\mathrm{g}$ & $2,45 \times 10^{6}$ & $1,68 \times 10^{9}$ & $4,12 \times 10^{15}$ & $5 \%$ \\
\hline Concreto & $\mathrm{g}$ & $7,73 \times 10^{6}$ & $1,54 \times 10^{9}$ & $1,19 \times 10^{16}$ & $14 \%$ \\
\hline Mudas & $\mathrm{J}$ & $2,00 \times 10^{8}$ & $4,58 \times 10^{3}$ & $9,16 \times 10^{11}$ & $<1 \%$ \\
\hline \multicolumn{4}{|c|}{ Total dos Recursos Provenientes da Economia (F) } & $1,69 \times 10^{16}$ & $20 \%$ \\
\hline \multicolumn{6}{|c|}{ Operação } \\
\hline \multicolumn{6}{|l|}{ Renováveis (R) } \\
\hline Chuva (Geopotencial) & $\mathrm{J}$ & $7,46 \times 10^{9}$ & $4,70 \times 10^{4}$ & $3,51 \times 10^{14}$ & $<1 \%$ \\
\hline Chuva (Química) & $\mathrm{J}$ & $4,18 \times 10^{11}$ & $3,05 \times 10^{4}$ & $1,27 \times 10^{16}$ & $16 \%$ \\
\hline Energia Geotérmica & $\mathrm{J}$ & $7,66 \times 10^{10}$ & $1,49 \times 10^{4}$ & $1,14 \times 10^{15}$ & $1 \%$ \\
\hline Irradiação solar* & $\mathrm{J}$ & $1,97 \times 10^{14}$ & 1 & $1,97 \times 10^{14}$ & $<1 \%$ \\
\hline Vento* & $\mathrm{J}$ & $3,18 \times 10^{11}$ & $2,45 \times 10^{3}$ & $7,79 \times 10^{14}$ & $1 \%$ \\
\hline \multicolumn{4}{|c|}{ Total dos Recursos Renováveis(R) } & $1,42 \times 1016$ & $18 \%$ \\
\hline \multicolumn{6}{|c|}{ Não Renováveis (N) } \\
\hline Solo Ocupado & $\mathrm{J}$ & $4,52 \times 10^{6}$ & $1,24 \times 10^{5}$ & $5,60 \times 10^{11}$ & $<1 \%$ \\
\hline \multicolumn{4}{|c|}{ Total dos Recursos Não Renováveis (N) } & $5,60 \times 1011$ & $<1 \%$ \\
\hline \multicolumn{6}{|c|}{ Provenientes da Economia $(F)$} \\
\hline Aço (equipamentos) & $\mathrm{kg}$ & 2541,67 & $4,15 \times 10^{9}$ & $1,05 \times 10^{13}$ & $<1 \%$ \\
\hline Algodão & $\mathrm{kg}$ & 2,97 & $1,44 \times 10^{6}$ & $4,28 \times 10^{6}$ & $<1 \%$ \\
\hline Mão de obra & $\mathrm{J}$ & $1,16 \times 10^{10}$ & $4,30 \times 10^{6}$ & $4,99 \times 10^{16}$ & $62 \%$ \\
\hline Mudas (árvores) & $\mathrm{J}$ & $2,53 \times 10^{9}$ & $4,58 \times 10^{3}$ & $1,16 \times 10^{13}$ & $<1 \%$ \\
\hline Papel & $\mathrm{kg}$ & 206,33 & $2,38 \times 10^{9}$ & $4,91 \times 10^{11}$ & $<1 \%$ \\
\hline Plástico & $\mathrm{kg}$ & 419,56 & $5,76 \times 10^{9}$ & $2,42 \times 10^{12}$ & $<1 \%$ \\
\hline Produtos Químicos & $\mathrm{kg}$ & 378,32 & $6,38 \times 10^{8}$ & $2,41 \times 10^{11}$ & $<1 \%$ \\
\hline \multicolumn{4}{|c|}{ Total dos Recursos Provenientes da Economia (F) } & $4,99 \times 1016$ & $62 \%$ \\
\hline \multicolumn{4}{|l|}{ Total $(\mathbf{R}+\mathbf{N}+\mathbf{F})$} & $8,10 \times 1016$ & $100 \%$ \\
\hline
\end{tabular}

*Os fluxos provêm da mesma fonte e não foram contabilizados para que não ocorra dupla contagem.

o que mostra que para sua manutenção o município deve investir de 5 a 10 vezes mais emergia do que aquela fornecida pela natureza. Este investimento é diretamente proporcional à razão entre a área verde e a área construída de cada parque e não há correlação com a quantidade de mão de obra empregada. Os resultados obtidos confirmam que na implantação dos parques do município, aparentemente, deu-se mais valor às atividades de lazer e à infraestrutura. $\mathrm{O}$ valor do emdólar por metro quadrado, levando em consideração os 73 parques, é de $0,55 \mathrm{Em} \$ / \mathrm{m}^{2}$. A Figura 2 apresenta os custos em função do $\mathrm{Em} \$ / \mathrm{m}^{2}$ e a razão $\mathrm{I} / \mathrm{F}$, com destaque para alguns parques que se encontram nos extremos da curva encontrada.

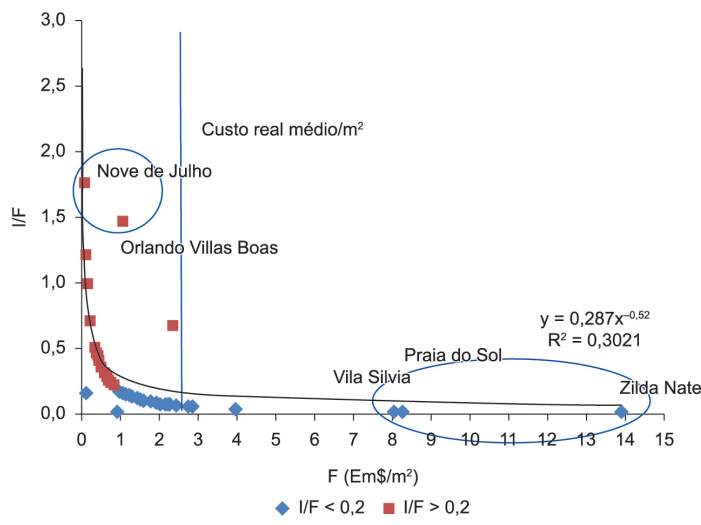

Figura 2. Custo em $\mathrm{Em} \$ / \mathrm{m}^{2}$ e a razão $\mathrm{I} / \mathrm{F}$ dos parques municipais de São Paulo. A linha vertical mostra o custo real em dólares $\left(2,71 \mathrm{U} \$ / \mathrm{m}^{2}\right)$. 
Observa-se que a relação entre I/F e o custo em $\mathrm{Em} \$ / \mathrm{m}^{2}$ dos parques obedece à equação empírica 1 (Equação 1), que pode fornecer uma relação prática entre a razão área verde/área contruída e custo.

$\mathrm{I} / \mathrm{F}=0,1666\left(\mathrm{Em} \$ / \mathrm{m}^{2}\right)^{-0,789}$

Os recursos fornecidos pelo município (concreto, plástico, papel, produtos químicos, mão de obra, etc.) são produtos processados e disponíveis em uma etapa avançada da cadeia produtiva, enquanto que os recursos que os parque captam diretamente do meio ambiente estão disponíveis no início da cadeia. Quanto mais se avança na cadeia, maior será o pagamento pela emergia recebida (Ton et al., 1998; Ukidwe \& Bakshi, 2005). Quanto maior a razão $\mathrm{I} / \mathrm{F}$ dos parques, menor será seu custo em emergia convertida para moeda. Assim, os parques com $\mathrm{I} / \mathrm{F}>0,2$ são os que menos custam por metro quadrado $\left(\mathrm{Em} \$ / \mathrm{m}^{2}\right)$. A linha azul vertical na Figura 2 mostra o custo real em dólares que foi calculado com os dados fornecidos pela SVMA (2010), de $2,71 \mathrm{U} \$ / \mathrm{m}^{2}$, que é 1,7 vezes maior que o da média calculada em emdólar $\left(\mathrm{Em} \$ / \mathrm{m}^{2}=1,59\right)$. Desta forma, de acordo com a metodologia empregada, pode-se sugerir que o município está em clara desvantagem quando compra os recursos necessários para a manutenção/operação destes sistemas existentes.

Os parques representados pelos pontos em vermelho ( $\mathrm{I} / \mathrm{F}>0,2)$, são aqueles que já contam com maior contribuição dos recursos naturais. Para aumentar a relação I/F, há duas possibilidades: aumentar a área verde ou reduzir os custos com manutenção e operação. Se nestes parques, o aumento de área verde não for possível (por exemplo, devido à sua localização), seria razoável propor melhorias para atenuar a carga exercida pela área construída para as atividades de lazer, como a utilização de estruturas que exijam menos manutenção e/ou pela redução da mão de obra empregada.

\subsection{Serviços ambientais: produção primária líquida (NPP), evapotranspiração e infiltração}

Foi realizado o cálculo da produção primária líquida (NPP) para a mata alta (árvores e arbustos) e para a grama em cada um dos parques em estudo. Três serviços ambientais estão associados (coprodutos) ao crescimento da biomassa. São eles: produção de $\mathrm{O}_{2}$, a absorção de $\mathrm{CO}_{2}$ e a evapotranspiração. A Tabela 3 mostra as quantidades em massa da biomassa, do $\mathrm{CO}_{2}$ fixado, do $\mathrm{O}_{2}$ produzido da evapotranspiração e da infiltração de água no solo no conjunto dos 73 parques.

A Tabela 4 ilustra um resumo com as entradas dos recursos renováveis e dos recursos fornecidos pela prefeitura para o conjunto dos 73 parques
Tabela 3. Quantidade biomassa, de $\mathrm{CO}_{2}$ fixado, $\mathrm{O}_{2}$ produzido, evapotranspiração e infiltração no conjunto de 73 parques estudados.

\begin{tabular}{ll}
\hline Quantidade de Biomassa & $2,84 \times 10^{10}(\mathrm{~g} / \mathrm{ano})$ \\
Quantidade de $\mathrm{CO}_{2}$ fixado & $1,74 \times 10^{10}(\mathrm{~g} / \mathrm{ano})$ \\
Quantidade de $\mathrm{O}_{2}$ produzido & $2,40 \times 10^{10}(\mathrm{~g} / \mathrm{ano})$ \\
Quantidade de água evapotranspirada & $1,65 \times 10^{7}\left(\mathrm{~m}^{3} / \mathrm{ano}\right)$ \\
Quantidade de água infiltrada & $1,05 \times 10^{7}\left(\mathrm{~m}^{3} / \mathrm{ano}\right)$ \\
\hline
\end{tabular}

Tabela 4. Resumo do suporte ambiental e da economia para os 73 parques em estudo e os serviços ambientais.

\begin{tabular}{lcr}
\hline & $\begin{array}{c}\text { Emergia } \\
\text { (seJ/ano) }\end{array}$ & Em\$/ano \\
\hline \multicolumn{3}{c}{ Suporte } \\
\hline R (ambiental) & $5,45 \times 10^{18}$ & $3.205 .882,35$ \\
F (municipal) & $1,09 \times 10^{19}$ & $6.411 .764,71$ \\
Total (R+F) & $\mathbf{1 , 6 4 \times 1 0 1 9}$ & $\mathbf{9 . 6 1 7 . 6 4 7 , 0 6}$ \\
\hline \multicolumn{4}{c}{ Serviços Ambientais } \\
\hline NPP & $1,66 \times 10^{18}$ & $976.470,59$ \\
CO2 & $6,24 \times 10^{17}$ & $367.058,82$ \\
O2 & $1,18 \times 10^{18}$ & $694.117,65$ \\
Evapotranspiração & $2,20 \times 10^{18}$ & $1.294 .117,65$ \\
Infiltração da água no solo & $7,17 \times 10^{18}$ & $4.217 .647,06$ \\
Total - (serviços & $\mathbf{9 , 3 7 \times 1 0 1 8}$ & $\mathbf{5 . 5 1 1 . 7 6 4 , 7 1}$ \\
ambientais) & & \\
\hline
\end{tabular}

estudados do município de São Paulo, os serviços ambientais fornecidos pelos parques para a cidade e os seus respectivos valores em emdólar. O delta negativo entre os serviços ambientais fornecidos pelos parques (áreas verdes) para a cidade e os recursos provenientes da economia empregados para sua manutenção/implantação é de 4.100.000 Em\$/ano aproximadamente. Por outro lado, deve-se também considerar que os serviços ambientais abatem $57 \%$ do custo total dos parques $(\mathrm{R}+\mathrm{F})$ ou aproximadamente $86 \%$ do total fornecido pela sociedade paulistana $(\mathrm{F})$. $\mathrm{O}$ valor de 4.100.000 Em\$/ano indica o equivalente em moeda, que poderia representar a parcela paga pela a sociedade para obter os serviços esperados dos parques urbanos, inclusive os serviços ambientais. Desta forma, considerando que a sociedade paulistana, como um todo, investe anualmente para a manutenção de seus parques, deve-se garantir que o acesso a estes serviços ocorra para toda a população da cidade de forma equânime.

Considerando que a prioridade para implantação de novos parques deve se dar em áreas densamente povoadas, nas quais a disponibilidade de terrenos seria menor, e contemplando a proposta de Lin et al. (2011) para otimizar a distribuição dos serviços destes parques, tomou-se uma amostra de 11 parques considerados pequenos no conjunto estudado. Com esta finalidade, os parques foram classificados em relação ao seu tamanho: pequenos - até $50.000 \mathrm{~m}^{2}$; 
médios - $50.000 \mathrm{~m}^{2}$ até $100.000 \mathrm{~m}^{2}$; e grandes - maiores de $100.000 \mathrm{~m}^{2}$. Dos 73 parques estudados tem-se 31 parques considerados pequenos, 17 médios e 25 grandes.

A Tabela 5 mostra o resumo dos suportes ambientais e da economia e os serviços ambientais fornecidos por 11 parques pequenos. O delta negativo entre $\mathrm{o}$ fornecimento de serviços ambientais e os recursos empregados para a sua manutenção/operação é de aproximadamente $300.000 \mathrm{Em} \$ /$ ano. Nesse caso, os serviços ambientais fornecidos por este conjunto de pequenos parques abatem apenas $24 \%$ de seu custo total $(\mathrm{R}+\mathrm{F})$ ou aproximadamente $28 \%$ do total fornecido pela sociedade paulistana (F). Dessa forma, sob a perspectiva custo/benefício, pode-se inferir que os parques pequenos oneram mais a sociedade e que, para aumentar a interface entre os parques e as vizinhanças por meio da implantação de parques pequenos (Lin et al., 2011), haveria consequente aumento no uso de recursos para sua manutenção/

Tabela 5. Resumo do suporte ambiental, econômico e dos serviços ambientais de uma amostra de 11 parques de pequeno porte da cidade de São Paulo.

\begin{tabular}{lcr}
\hline & $\begin{array}{r}\text { Emergia } \\
\text { (seJ/ano) }\end{array}$ & Em\$/ano \\
\hline \multicolumn{3}{c}{ Suporte } \\
\hline $\mathrm{R}$ (ambiental) & $9,43 \times 10^{16}$ & $55.460,36$ \\
$\mathrm{~F}$ (municipal) & $5,87 \times 10^{17}$ & $345.185,39$ \\
Total & $\mathbf{6 , 8 1} \times \mathbf{1 0 1 7}$ & $\mathbf{4 0 0 . 6 4 5 , 7 5}$ \\
\hline \multicolumn{3}{c}{ Serviços Ambientais } \\
\hline $\mathrm{NPP}$ & $3,01 \times 10^{16}$ & $17.703,94$ \\
$\mathrm{CO}_{2}$ & $1,13 \times 10^{16}$ & $6.674,32$ \\
$\mathrm{O}_{2}$ & $2,15 \times 10^{16}$ & $12.618,63$ \\
Evapotranspiração & $3,00 \times 10^{16}$ & $22.770,59$ \\
Infiltração da água no solo & $1,24 \times 10^{17}$ & $72.741,18$ \\
Total - (serviços ambientais) & $\mathbf{1 , 6 2 \times \mathbf { 1 0 1 7 }}$ & $\mathbf{9 5 . 5 1 1 , 7 6}$ \\
\hline
\end{tabular}

Tabela 6. Resumo do suporte ambiental, econômico e dos serviços ambientais de uma amostra de 17 parques de médio porte da cidade de São Paulo.

\begin{tabular}{lcc}
\hline & $\begin{array}{c}\text { Emergia } \\
\text { (seJ/ano) }\end{array}$ & Em\$/ano \\
\hline \multicolumn{3}{c}{ Suporte } \\
\hline R (ambiental) & $4,79 \times 10^{17}$ & $281.836,98$ \\
F (municipal) & $2,07 \times 10^{18}$ & $1.217 .091,74$ \\
Total (R+F) & $\mathbf{2 , 5 5 \times 1 0 1 8}$ & $\mathbf{1 . 4 9 8 . 9 2 8 , 7 2}$ \\
\hline \multicolumn{3}{c}{ Serviços Ambientais } \\
\hline NPP & $1,04 \times 10^{17}$ & $61.094,21$ \\
CO2 & $3,91 \times 10^{16}$ & $23.023,44$ \\
O2 & $7,40 \times 10^{16}$ & $694.117,65$ \\
Evapotranspiração & $1,42 \times 10^{17}$ & $83.300,96$ \\
Infiltração da água no solo & $4,70 \times 10^{17}$ & $276.600,04$ \\
Total (serviços ambientais) & $\mathbf{6 , 1 2 \times 1 0 1 7}$ & $\mathbf{3 5 9 . 9 0 1 , 0 0}$ \\
\hline
\end{tabular}

implantação. Deve-se ressaltar que Oliveira et al. (2011) analisaram o desempenho térmico de um pequeno espaço verde $\left(24.000 \mathrm{~m}^{2}\right)$ sem comprovar a influência desta área verde na vizinhança densamente urbanizada.

Considerando os resultados de Dimoudi \& Nikolopoulou (2003), que alegam que o aumento no tamanho da área verde urbana reduz efetivamente a temperatura do ar ambiente, e os resultados de Oliveira et al. (2011), efetuou-se a análise para um conjunto de 17 parques com área entre $50.000 \mathrm{~m}^{2} \mathrm{e}$ $100.000 \mathrm{~m}^{2}$. O delta negativo é de aproximadamente 1.100.000 Em\$/ano (Tabela 6), o que mostra que, ainda neste caso, a prefeitura paga para obter os serviços ambientais, porém este valor corresponde a apenas $26 \%$ do total. Os serviços ambientais fornecidos por este conjunto de pequenos parques abatem $24 \%$ de seu custo total $(\mathrm{R}+\mathrm{F})$ ou aproximadamente $30 \%$ do total fornecido pela sociedade $(\mathrm{F})$.

$\mathrm{Na}$ análise para 25 parques com área superior a $100.000 \mathrm{~m}^{2}$ observa-se que o valor dos serviços ambientais fornecidos para a cidade supera o dos recursos empregados para sua manutenção/ implantação (Tabela 7). Neste caso, a diferença mostra que a sociedade recebe um benefício líquido de aproximadamente 1.200.000 Em\$/ano em serviços ambientais.

A contabilidade ambiental em emergia não permite avaliar o alcance dos serviços ambientais nas vizinhanças, mas somente a contribuição de cada parque ou do conjunto para o sistema que o abastece e o rodeia. De acordo com a avaliação custo/benefício efetuada, a implantação de parques de pequeno porte (Lin et al., 2011), mesmo com $60 \%$ ou mais de áreas verdes, não seria recomendada. Somente no caso de parques com mais de $100.000 \mathrm{~m}^{2}$ verificou-se benefício líquido na produção de serviços ambientais. Neste caso, para cada emdólar investido na manutenção e implantação

Tabela 7. Resumo do suporte ambiental, econômico e dos serviços ambientais de uma amostra de 25 parques de grande porte da cidade de São Paulo.

\begin{tabular}{|c|c|c|}
\hline & $\begin{array}{l}\text { Emergia } \\
\text { (seJ/ano) }\end{array}$ & Em\$/ano \\
\hline \multicolumn{3}{|c|}{ Suporte } \\
\hline $\mathrm{R}$ (ambiental) & $2,86 \times 10^{18}$ & $1.680 .623,53$ \\
\hline F (municipal) & $2,29 \times 10^{17}$ & $134.449,02$ \\
\hline Total $(\mathbf{R}+\mathbf{F})$ & $3,09 \times 1018$ & $1.815 .072,55$ \\
\hline \multicolumn{3}{|c|}{ Serviços Ambientais } \\
\hline NPP & $9,71 \times 10^{17}$ & $571.007,38$ \\
\hline $\mathrm{CO} 2$ & $3,66 \times 10^{17}$ & $215.155,96$ \\
\hline $\mathrm{O} 2$ & $6,92 \times 10^{17}$ & $406.779,24$ \\
\hline Evapotranspiração & $1,23 \times 10^{18}$ & $720.668,26$ \\
\hline Infiltração & $3,87 \times 10^{18}$ & $2.275 .021,34$ \\
\hline Total (serviços ambientais) & $5,09 \times 1018$ & $2.995 .689,60$ \\
\hline
\end{tabular}


dos parques de grande porte, os benefícios retornam na proporção de 1,65:1. Este resultado é semelhante ao encontrado por McPherson et al. (2005), que determinaram um intervalo entre US\$1,37 e US\$3,09 ao ano para cada dólar investido na manutenção de florestas urbanas com áreas maiores de $100.000 \mathrm{~m}^{2}$.

\section{Discussão}

Com a utilização da síntese em emergia, foi possível quantificar o investimento da sociedade e da natureza na implantação/operação de um conjunto de 73 parques municipais de São Paulo e avaliar os serviços ambientais prestados à cidade por meio dos processos de Evapotranspiração, Produção Primária Líquida de Biomassa (NPP, Net Primary Production) e Infiltração na água no solo.

Com o cálculo da emergia total e dos indicadores em emergia de cada parque foi possível reconhecer e quantificar os fatores que determinam os custos em emergia de cada parque e avaliar seu desempenho ambiental. Observou-se que a cidade tem parques com todos os tipos de configurações (área verde/ área construída) e foram identificados parques que realmente podem contribuir para reduzir a carga ambiental da cidade, ou pelo menos de seus arredores. Há casos extremos de dois tipos:

- aqueles que utilizam principalmente recursos naturais gratuitos e que em proporção requerem pouco investimento da sociedade. Calculados os indicadores, estes parque apresentam altos valores de ESI e EYR e baixos valores de EIR e ELR (Anexo B, Tabela B1).

Nesse caso, se pode citar os parques Anhanguera, Linear Cocaia, Nove de Julho, Orlando Villas Boas, Vila do Rodeio, Cemucam, Linear Castelo e Luiz Carlos Prestes. Estes parques possuem grandes áreas verdes (de aproximadamente $90 \%$ da área total), mas estão distantes do centro da cidade. Infelizmente seria muito difícil conseguir instalar este tipo de parque nas áreas mais centrais, mas vale lembrar que a preservação destas áreas deve ser mantida pela prefeitura.

- e aqueles que dependem prioritariamente dos recursos econômicos do município para sua operação/manutenção. Calculados os indicadores, estes parque apresentam baixos valores de ESI e EYR e altos valores de EIR e ELR (Anexo B).

A maioria dos parques em estudo são do segundo tipo, com casos extremos como os parques Zilda Natel, Praia do Sol e Vila Silvia, em que a carga imposta ao sistema externo é extremamente grande. Entretanto, estes parques exercem uma função social suprindo a demanda de lazer da população local.
Do cálculo das emergias dos serviços ambientais (NPP, Evapotranspiração e Infiltração), é possível estabelecer uma relação custo/benefício entre a produção de serviços ambientais e o investimento do município. Apesar de a contabilidade ambiental em emergia não avaliar o alcance dos serviços ambientais nas vizinhanças (extensão do raio para resfriamento ou absorção de poluentes), o valor da emergia (e de seu equivalente em moeda) representam a parcela paga pela sociedade para obter os serviços esperados dos parques urbanos.

\section{Conclusões}

Este trabalho contribui para a compreensão do sistema de fornecimento de serviços ambientais por parques urbanos, mas principalmente oferece ferramentas para a tomada de decisão no que concerne à instalação e gerenciamento de parques urbanos.

A comparação dos custos de implantação/operação em dólares, em emdólares e a razão entre os recursos naturais e econômicos ( $\mathrm{I} / \mathrm{F}$ x Em $\$ / \mathrm{m}^{2}$ ) pode ser uma ferramenta para determinar a configuração ideal para projetar novos parques na cidade de São Paulo. A relação entre I/F e Em $\$ / m^{2}$ (ou US\$) pode ser empregada como ferramenta para tomada de decisão para priorizar ações nos parques existentes e para implantar novos projetos.

Neste caso, pode-se determinar:

1) a relação área verde/área construída

2) a área do parque

Para estabelecer a relação entre a área verde e a área construída, é necessário encontrar um balanço entre os valores I e F, para a obtenção de estruturas que possam fornecer ao município os serviços desejados. Por meio da contabilidade dos recursos naturais disponíveis (I) e do investimento feito pela sociedade $(\mathrm{F})$, é possível determinar:

a) a relação I/F para que os parques que produzem predominantemente serviços ambientais tenham menor custo por metro quadrado (Figura 2, pontos em vermelho);

b) a relação I/F para que os parques voltados a oferecer princilpalmente atividades de lazer cultura e recreação tenham menor custo por metro quadrado (Figura 2, pontos em azul);

c) qual a relação I/F para que os parques "completos" produtores de serviços ambientais, lazer, educação e cultura tenham menor custo por metro quadrado (Figura 2), maximizando a produção de serviços e otimizando os custos. 
Quando os parques são avaliados em função de sua área, verifica-se que a operação dos parques com menos de $100.000 \mathrm{~m}^{2}$ resulta em aumento no uso de recursos do município para sua manutenção/ implantação. Por outro lado, observa-se que o valor em emergia dos serviços ambientais fornecidos para a cidade pelos parques com mais de $100.000 \mathrm{~m}^{2}$ supera o dos recursos provenientes da economia. Os valores de custo/benefício calculados indicam que a sociedade paulistana arca com os custos de manutenção de seus parques.

\section{Referências}

Akbari, H., Pomerantz, M., \& Taha, H. (2001). Cool surfaces and shade trees to reduce energy use and improve air quality in urban areas. Solar Energy, 70(3), 295-310. http://dx.doi.org/10.1016/S0038092X(00)00089-X.

Almeida, C. M. V. B., Barrella, F. A., \& Giannetti, B. F. (2007). Emergetic ternary diagrams: five examples for application in environmental accounting for decisionmaking. Journal of Cleaner Production, 15(1), 63-74. http://dx.doi.org/10.1016/j.jclepro.2005.07.002.

Bolund, P., \& Hunhammar, S. (1999). Ecosystem services in urban areas. Ecological Economics, 29(2), 293-301. http://dx.doi.org/10.1016/S0921-8009(99)00013-0.

Brabec, E., Schulte, S., \& Richards, P. L. (2002). Impervious surfaces and water quality: a review of current literature and its implications for watershed planning. Journal of Planning Literature, 16(4), 499-514. http:// dx.doi.org/10.1177/088541202400903563.

Centro de Previsão de Tempo e Estudos Climáticos CPTEC (2010). Índices pluviométrico. Recuperado em 02 de janeiro de 2011, de http://www.cptec.inpe.br

Centro de Referência para Energia Solar e Eólica Sergio Brito - CRESESB (2011). Insolação anual. Recuperado em 19 de março de 2011, de http://www.cresesb. cepel.br

Chen, W. Y., \& Jim, C. Y. (2008). Assessment and valuation of the ecosystem services provided by urban forests. In M. M. Carreiro, Y.-C. Song \& J. Wu (Eds.), Ecology, planning, and management of urban forests: international perspectives (pp. 53-83). New York: Springer.

Conway, T. M., \& Urbani, L. (2007). Variations in municipal urban forestry policies: a case study of Toronto, Canada. Urban Forestry \& Urban Greening, 6(3), 181-192. http://dx.doi.org/10.1016/j. ufug.2007.07.003.

Dang, X., \& Liu, G. (2012). Emergy measures of carrying capacity and sustainability of a target region for an ecological restorations programme: a case study in Loess Hilly Region, China. Journal of Environmental Management, 102, 55-64. PMID:22425879
Demetrio, F. J. C. (2011). Avaliação da sustentabilidade do Brasil com a contabilidade em emergia (Tese de doutorado). Universidade Paulista, São Paulo.

Dimoudi, A., \& Nikolopoulou, M. (2003). Vegetation in the urban environment: microclimatic analysis and benefits. Energy and Building, 35(1), 69-76. http:// dx.doi.org/10.1016/S0378-7788(02)00081-6.

Duan, N., Liu, X. D., Dai, J., Lin, C., Xia, X. H., Gao, R. Y., Wang, Y., Chen, S. Q., Yang, J., \& Qi, J. (2011). Evaluating the environmental impacts of an urban wetland park based on emergy accounting and life cycle assessment: a case study in Beijing. Ecological Modelling, 222(2), 351-359.

Escobedo, F. J., Wagner, J. E., Nowak, D. J., De la Maza, C. L., Rodriguez, M., \& Crane, D. E. (2008). Analyzing the cost effectiveness of Santiago, Chile's policy of using urban forests to improve air quality. Journal of Environmental Management, 86(1), 148-157. http://dx.doi.org/10.1016/j.jenvman.2006.11.029. PMid:17275162

Giannetti, B. F., Barrela, F. A., \& Almeida, C. M. V. B. (2006). A combined tool for environmental scientists and decision makers: ternary diagrams and emergy accounting. Journal of Cleaner Production, 14(2), 201210. http://dx.doi.org/10.1016/j.jclepro.2004.09.002.

Giannetti, B. F., Ogura, Y., Bonilla, S. H., \& Almeida, C. M. V. B. (2011). Emergy assessment of a coffee farm in Brazilian Cerrado considerering form the environmental services, negative externalities and fair price. Agricultural Systems, 104(9), 679-688.

Google (2012). Google earth. Recuperado em 04 de julho de 2012, de http://earth.google.com

Higgins, J. B. (2003). Emergy analysis of the Oak Openings region. Ecological Engineering, 21(1), 75-109. http://dx.doi.org/10.1016/j.ecoleng.2003.09.007.

Huang, S. L., Wang, S. H., \& Budd, W. W. (2009). Sprawl in Taipei"s peri-urban zone: responses to spatial planning and implication for adapting global environmental change. Landascape and Urban Planning, 90(1-2), 20-32. http://dx.doi.org/10.1016/j.landurbplan.2008.10.010.

Instituto Brasileiro de Geografia e Estatística - IBGE, Ministério do Planejamento, Orçamento e Gestão (2011). Cidades. Rio de Janeiro: IBGE. Recuperado em 2 de novembro de 2011, de http://www.ibge.gov. br/cidadesat/topwindow.html

Kliass, R. G. (1993). Parques urbanos de São Paulo. São Paulo: PINI. 211 p.

Lin, W., Wu, T., Zhang, C., \& Yu, T. (2011). Carbon savings resulting from the cooling effect of green areas: a case study in Beijing. Environmental Pollution, 159(8-9), 2148-2154. http://dx.doi.org/10.1016/j.envpol.2011.02.035. PMid:21444136

Lu, H. F., Campbell, D. E., Li, Z. A, \& Ren, H. (2005). 
Emergy synthesis of an agro-forest restoration system in lower subtropical China. Ecological Engineering, 27, 175-192. http://dx.doi.org/10.1016/j.ecoleng.2005.12.002.

McPherson, E. G., \& Simpson, J. R. (2002). A comparison of municipal forest benefits and costs in Modesto and Santa Monica, California, USA. Urban Forestry \& Urban Greening, 1(2), 61-74. http://dx.doi. org/10.1078/1618-8667-00007.

McPherson, G., Simpson, J. R., Peper, P. J., Maco, S. E., \& Xiao, Q. (2005). Municipal forest benefits and costs in five US cities. Journal of Forestry, 103, 411-416.

Meyer, W. B., \& Turner, B. L. (1994). Changes in land use and land cover: a global perspective. New York: Cambridge University Press.

Millward A. A., \& Sabir S. (2011). Benefits of a forested urban park: what is the value of Allan Gardens to the city of Toronto, Canada? Landscape and Urban Planning, 100, 177-188. http://dx.doi.org/10.1016/j.landurbplan.2010.11.013.

Nowak, D. J., \& Dwyer, J. F. (2000). Understanding the benefits and costs of urban forest ecosystems. In J. E. Kuser (Ed.), Handbook of urban and community forestry in the Northeast (pp. 11-25). New York: Kluwer Academic.

Odum, H. T. (1996). Environmental accounting: emergy and decision making. New York: John Wiley \& Sons. $370 \mathrm{p}$.

Odum, H. T., Doherty, S. J., Scatena, F. N., \& Kharecha, P. (2000). Emergy evaluation of reforestation alternatives in Puerto Rico. Forest Science, 46(4), 521-530.

Oliveira, S., Andrade, H., \& Vaz, T. (2011). The cooling effect of green spaces as a contribution to the mitigation of urban heat: A case study in Lisbon. Building and Environment, 46(11), 2186-2194. http://dx.doi. org/10.1016/j.buildenv.2011.04.034.

Qin, P., Wong, Y. S., \& Tam, N. F. Y. (2000). Emergy evaluation of Mai Po mangrove marshes. Ecological Engineering, 16(2), 271-280. http://dx.doi.org/10.1016/ S0925-8574(00)00104-X.

Rosenfeld, A. H., Akbari, H., Bretz, S., Fishman, B. L., Kurn, D. M., Sailor, D., \& Taha, H. (1995). Mitigation of urban heat islands: materials, utility programs, updates. Energy and Building, 22(3), 255-265. http:// dx.doi.org/10.1016/0378-7788(95)00927-P.
Secretaria do Verde e Meio Ambiente - SVMA (2010). Sâo Paulo: Parques. Recuperado em 18 de março de 2010, de http://www.prefeitura.sp.gov.br/cidade/secretarias/meio_ambiente/

Silva, L. O. (1993). Subsídios para formulação de uma política para áreas verdes no Município de São Paulo. In A. Phillipi Jr. (Ed.), A questão ambiental urbana: cidade de São Paulo (pp. 425-449). São Paulo: SVMA.

Su, C., Fu, B., He, C., \& Lü Y. (2012). Variation of ecosystem services and human activities: a case study in the Yanhe Watershed of China. Acta Oecologica, 44, 46-57.

Tilley, D. R., \& Swank, W. T. (2003). Emergy-based environmental systems assessment of a multi-purpose temperate mixed-forest watershed of the southern Appalachian Mountains, USA. Journal of Environmental Management, 69(3), 213-227. http://dx.doi. org/10.1016/j.jenvman.2003.08.002. PMid:14580723

Ton, S., Odum, H. T., \& Delfino, J. (1998). Ecologicaleconomic evaluation of wetland management alternatives. Ecological Engineering, 11, 291-302. http:// dx.doi.org/10.1016/S0925-8574(98)00039-1.

Ukidwe, N. U., \& Bakshi, B. R. (2005). Flow of natural versus economic capital in industrial supply networks and its implications to sustainability. Environmental Science \& Technology, 39(24), 9759-9769. http:// dx.doi.org/10.1021/es050627n. PMid:16475364

Ulgiati, S., Zucaro, A., \& Franzese, P. P. (2010). Shared wealth or nobody's land? The worth of natural capital and ecosystem services. Ecological Economics, 70(4):778-787. http://dx.doi.org/10.1016/j. ecolecon.2010.11.015.

Xiao, Q., \& McPherson, E. G. (2002). Rainfall interception by Santa Monica's municipal urban forest. Urban Ecology, 6(4), 291-302. http://dx.doi.org/10.1023/ B:UECO.0000004828.05143.67.

Xiao, Q., McPherson, E. G., Simpson, J. R., \& Ustin, S. L. (1998). Rainfall interception by Sacramento's urban forest. Journal of Arboriculture, 24, 235-244.

Zhao, S., Da, L., Tang, Z., Fang, H., Song, K., \& Fang, J. (2006). Ecological consequences of rapid urban expansion: Shangai, China. Research Communications, 4(7), 341-346. 
Anexo A. Roteiro para cálculo dos serviços ambientais.

\section{A1. Produção primária líquida (NPP)}

A Equação 1A expressa a energia da NPP. Foram efetuados cálculos separados para a mata alta e para a área gramada. A energia da massa seca utilizada no cálculo da energia da produção primária líquida (NPP) para a mata alta foi de $2,16 \times 10^{7} \mathrm{~J} / \mathrm{ano} \mathrm{m}^{2}$ (Lu et al., 2005) e a energia de massa seca utilizada no cálculo da NPP da grama foi de 7,60 x $10^{6} \mathrm{~J} / \mathrm{ano} \mathrm{m}^{2}$ (Lu et al., 2005).

$$
\text { Energia }_{\mathrm{NPP}}=\text { área verde }\left(\mathrm{m}^{2}\right) \times \text { energia da massa seca }\left(\frac{\mathrm{J}}{\mathrm{m}^{2} \text { ano }}\right)
$$

A emergia da NPP é o produto entre a energia da produção primária líquida (NPP) e UEV (Equação 2A). A UEV usada neste trabalho para a mata alta foi de 5,54 x $103 \mathrm{seJ} / \mathrm{J}$ e da grama 4,26 x 10 $\mathrm{seJ} / \mathrm{J}$ (Lu et al., 2005). A emergia total da NPP inclui a mata alta e a grama (Equação 3A).

$$
\begin{gathered}
\text { Emergia }_{N P P}=\text { Energia }_{N P P}\left(\frac{J}{\text { ano }}\right) \times U \mathrm{EV}\left(\frac{\text { seJ }}{J}\right) \\
\text { Emergia }_{\mathrm{NPP}}=\text { Emergia mata alta }\left(\frac{\text { seJ }}{\text { ano }}\right)+\text { Emergia grama }\left(\frac{\text { seJ }}{\text { ano }}\right)
\end{gathered}
$$

A Equação 4A ilustra a quantidade de biomassa produzida em cada parque. Neste trabalho, utilizou-se o valor de $1.150 \mathrm{~g} / \mathrm{m}^{2}$ ano para a massa seca da mata alta (Lu et al., 2005) e $2980 \mathrm{~g} / \mathrm{m}^{2}$ ano para a grama (Lu et al., 2005).

$$
\text { Quantidade }_{\text {biomassa }}=\text { área verde }\left(\mathrm{m}^{2}\right) \times \text { massaseca }\left(\frac{\mathrm{g}}{\mathrm{m}^{2} \text {.ano }}\right)
$$

\section{A.2. Fixação de $\mathrm{CO} 2$ e produção de $\mathrm{O} 2$}

As Equações $5 \mathrm{~A}$ e $6 \mathrm{~A}$ ilustram os cálculos para a quantidade de $\mathrm{CO}_{2}$ fixado e a quantidade de $\mathrm{O}_{2}$ produzido em cada parque.

$$
\begin{aligned}
& \text { Quantidade } \mathrm{CO}_{2} \text { fixado }=\text { quantidade de biomassa }\left(\frac{\mathrm{g}}{\text { ano }}\right) \times 0,614 \\
& \text { Quantidade }_{\mathrm{O} 2 \text { produzido }}=\text { quantidade }_{\mathrm{CO}_{2} \text { fixado }}\left(\frac{\mathrm{g}}{\text { ano }}\right) \times \frac{44}{32}
\end{aligned}
$$

sendo 0,614 o coeficiente de transformação de $\mathrm{CO}_{2}$ para biomassa. As Equações 7A e 8A são utilizadas para o cálculo da obtenção da energia de fixação de $\mathrm{CO}_{2}$ e a energia de produção de $\mathrm{O}_{2}$.

$$
\begin{aligned}
& \text { Energia } \mathrm{CO}_{2} \text { fixado }=\text { energia da biomassa (NPP) }\left(\frac{\mathrm{J}}{\text { ano }^{2}}\right) \times 0,614 \\
& \text { Energia } \mathrm{O}_{2} \text { produzido }=\text { energia da biomassa (NPP) }\left(\frac{\mathrm{J}}{\text { ano }^{2}}\right) \times \frac{44}{32}
\end{aligned}
$$

A UEV da fixação de $\mathrm{CO}_{2}$ é calculada pela razão entre a emergia e a energia da NPP, multiplicada por 0,614 (Equação 9A). A UEV da produção de $\mathrm{O}_{2}$ é calculada de acordo com a Equação 10A.

$$
\begin{aligned}
& \mathrm{UEV}_{\text {fixação de } \mathrm{CO}_{2}}=\frac{\text { Emergia }_{\mathrm{NPP}} \times 0,614}{\text { Energia NPP }} \\
& \mathrm{UEV}_{\text {produção de } \mathrm{O}_{2}}=\frac{\text { Emergia }_{\mathrm{NPP}} \times 0,614}{\text { Energia do NPP }} \times \frac{44}{32}
\end{aligned}
$$




\section{A.3. Evapotranspiração}

Foram efetuados cálculos separados para a mata alta e para a área gramada, devido aos diferentes valores do índice de evaporação de cada tipo de vegetação e às áreas de cada tipo de vegetação que diferem em cada parque. O índice de evapotranspiração utilizado para a mata alta foi 1006,2 mm/ano e para a grama foi de 8,321 x 10-1 m/ano (Lu et al., 2005). A Equação 11A expressa o volume de evapotranspiração em uma determinada área e a energia da evapotranspiração (Equação 12A) é o produto entre o volume total de evapotranspiração e a Energia Livre de Gibbs $\left(4,94\right.$ x $\left.10^{6} \mathrm{~J} / \mathrm{m}^{3}\right)$.

$$
\begin{gathered}
\text { Volume }_{\text {Evapotranspiração }}=\text { índice }_{\text {Evapotranspiração }}\left(\frac{\mathrm{m}}{\text { ano }}\right) \times \text { área }\left(\mathrm{m}^{2}\right) \\
\text { Energia }_{\text {Evapotranspiração }}=\text { Volume }_{\text {Evapotranspiração }}\left(\frac{\mathrm{m}^{3}}{\text { ano }}\right) \times \text { Energia Livre de Gibbs }\left(\frac{\mathrm{J}}{\mathrm{m}^{3}}\right)
\end{gathered}
$$

A Equação 13A fornece a emergia da evapotranspiração de cada parque, sendo a emergia total de evapotranspiração obtida pela soma das emergias calculadas para a evapotranspiração da mata alta e da área gramada (Equação 14A).

$$
\begin{gathered}
\text { Emergia }{ }_{\text {Evapotranspiração }}=\text { Energia }_{\text {evapotranspiração }} \times \mathrm{UEV}_{\text {evapotranspiração }} \\
\text { Emergia Total }{ }_{\text {Evapotranspiração }}=\text { Emergia }_{\text {evapo(mata alta) }}+\text { Emergia }_{\text {evapo(grama) }}
\end{gathered}
$$

\section{A.3. Infiltração}

A infiltração da água no solo consiste na passagem de água da superfície para o interior do solo. A Equação 15A representa a diferença entre o volume de chuva real (Equação 16A) e o volume de evapotranspiração. A precipitação média mensal na cidade de São Paulo é de $145 \mathrm{~mm} / \mathrm{mês}$ (CPTEC, 2010) e o escoamento superficial nos parques representa $10 \%$ da precipitação total. A emergia da infiltração da água no solo (Equação 17A) é o produto entre o volume total de infiltração e a UEV = 6,85 x $10^{11} \mathrm{seJ} / \mathrm{m}^{3}$.

$$
\begin{gathered}
\text { Volume }_{\text {infiltração }}=\text { Volume }_{\text {precipitação }}-\text { Volume }_{\text {evapotranspiração }} \\
\text { Volume }_{\text {precipitação }}=\text { quantidade }_{\text {precipitação }}\left(\frac{\mathrm{L}}{\mathrm{m}^{2} \text { mês }}\right) \times \text { área }\left(\mathrm{m}^{2}\right) \times\left(12 \times \frac{\mathrm{mês}}{\text { ano }} \times \frac{\mathrm{m}^{3}}{1000 \mathrm{~L}}\right) \\
\text { Emergia }_{\text {infiltração }}=\text { Volume }_{\text {infiltração }} \times \mathrm{UEV}_{\text {infiltração }}
\end{gathered}
$$


Anexo B. Cálculo dos indicadores EIR, EYR, ELR e ESI para os parques urbanos de São Paulo.

Tabela 1B. Cálculo dos indicadores em emergia a partir das quantidades de recursos renováveis $(\mathrm{R})$, não renováveis $(\mathrm{N})$ e povenientes da economia $(\mathrm{F})$.

\begin{tabular}{|c|c|c|c|c|c|c|c|c|}
\hline Parques & $\begin{array}{c}\mathbf{R} \\
\left(x 10^{17} \frac{\mathrm{seJ}}{\mathrm{ano}}\right)\end{array}$ & $\begin{array}{c}\mathbf{N} \\
\left(x 10^{13} \frac{\mathrm{seJ}}{\mathrm{ano}}\right)\end{array}$ & $\begin{array}{c}\mathbf{F} \\
\left(x 10^{17} \frac{\mathrm{seJ}}{\mathrm{ano}}\right)\end{array}$ & $\left(\frac{\mathrm{Em}(\mathrm{Y}) \$}{\mathrm{~m}^{2}}\right)$ & EIR & EYR & ELR & ESI \\
\hline Anhanguera & 28,57 & 0,41 & 2,29 & 0,19 & 0,08 & 13,50 & 0,08 & 168,75 \\
\hline Linear Cocaia & 3,72 & 0,07 & 0,33 & 0,24 & 0,09 & 12,12 & 0,09 & 134,88 \\
\hline Nove de Julho & 1,50 & 0,14 & 0,86 & 0,28 & 0,57 & 2,76 & 0,57 & 4,84 \\
\hline Orlando Villas Boas & 1,49 & 0,15 & 1,02 & 2,69 & 0,68 & 2,47 & 0,68 & 3,61 \\
\hline Vila do Rodeio & 1,84 & 0,14 & 1,52 & 0,32 & 0,82 & 2,21 & 0,82 & 2,69 \\
\hline Cemucam & 1,47 & 0,18 & 1,49 & 0,35 & 1,02 & 1,98 & 1,02 & 1,95 \\
\hline Linear Castelo & 0,31 & 0,02 & 0,44 & 0,43 & 1,43 & 1,70 & 1,43 & 1,19 \\
\hline Luiz Carlos Prestes & 0,74 & 0,16 & 1,09 & 3,97 & 1,48 & 1,67 & 1,48 & 1,13 \\
\hline Alfredo Volpi & 0,42 & 0,01 & 0,84 & 0,52 & 2,01 & 1,50 & 2,01 & 0,75 \\
\hline Ciência & 0,56 & 0,14 & 1,25 & 0,57 & 2,22 & 1,45 & 2,22 & 0,65 \\
\hline Linear Água Vermelha & 0,37 & 0,14 & 0,85 & 0,58 & 2,28 & 1,44 & 2,28 & 0,63 \\
\hline Santo Dias & 0,40 & 0,11 & 0,92 & 0,58 & 2,30 & 1,43 & 2,30 & 0,62 \\
\hline Linear Itaim & 0,18 & 0,04 & 0,45 & 0,62 & 2,49 & 1,40 & 2,49 & 0,56 \\
\hline Guarapiranga & 0,46 & 0,06 & 1,20 & 0,64 & 2,63 & 1,38 & 2,63 & 0,53 \\
\hline Previdência & 0,27 & 0,07 & 0,72 & 0,63 & 2,67 & 1,37 & 2,67 & 0,51 \\
\hline Guanhembú & 0,22 & 0,04 & 0,62 & 0,68 & 2,88 & 1,35 & 2,88 & 0,47 \\
\hline Barragem Guarapiranga & 0,26 & 0,20 & 0,87 & 0,76 & 3,31 & 1,30 & 3,31 & 0,39 \\
\hline Jardim Herculano & 0,23 & 0,14 & 0,77 & 0,78 & 3,43 & 1,29 & 3,43 & 0,38 \\
\hline Shangrilá & 0,23 & 0,14 & 0,80 & 0,80 & 3,54 & 1,28 & 3,54 & 0,36 \\
\hline Sete Campos & 0,56 & 0,48 & 2,17 & 0,86 & 3,84 & 1,26 & 3,84 & 0,33 \\
\hline Pinheirinho D ‘ Água & 0,75 & 0,50 & 2,86 & 0,85 & 3,82 & 1,26 & 3,82 & 0,33 \\
\hline Linear Canivete & 0,18 & 0,14 & 0,72 & 0,88 & 4,01 & 1,25 & 4,01 & 0,31 \\
\hline Linear Rapadura & 0,21 & 0,14 & 0,90 & 0,93 & 4,27 & 1,23 & 4,27 & 0,29 \\
\hline Linear Sapé & 0,07 & 0,02 & 0,29 & 0,90 & 4,22 & 1,24 & 4,22 & 0,29 \\
\hline Linear Tiquatira & 0,96 & 1,23 & 4,03 & 0,92 & 4,22 & 1,24 & 4,22 & 0,29 \\
\hline Piqueri & 0,29 & 0,17 & 1,27 & 0,95 & 4,37 & 1,23 & 4,37 & 0,28 \\
\hline Trianon & 0,14 & 0,06 & 0,67 & 0,98 & 4,69 & 1,21 & 4,69 & 0,26 \\
\hline Jacques Cousteau & 1,00 & 1,62 & 4,75 & 1,01 & 4,75 & 1,21 & 4,75 & 0,25 \\
\hline Sena & 0,07 & 0,07 & 0,36 & 1,16 & 5,49 & 1,18 & 5,49 & 0,22 \\
\hline São Domingos & 0,24 & 0,30 & 1,27 & 1,11 & 5,32 & 1,19 & 5,32 & 0,22 \\
\hline Raposo Tavares & 0,57 & 0,90 & 3,02 & 1,08 & 5,30 & 1,19 & 5,30 & 0,22 \\
\hline Águas & 0,23 & 0,68 & 1,28 & 1,16 & 5,65 & 1,18 & 5,65 & 0,21 \\
\hline Severo Gomes & 0,10 & 0,07 & 0,61 & 1,21 & 5,85 & 1,17 & 5,85 & 0,20 \\
\hline Lajeado & 0,11 & 0,14 & 0,63 & 1,20 & 5,84 & 1,17 & 5,84 & 0,20 \\
\hline Jardim Sapopemba & 0,11 & 0,19 & 0,66 & 0,13 & 5,98 & 1,17 & 5,99 & 0,19 \\
\hline Cohab Raposo Tavares & 0,15 & 1,36 & 3,46 & 3,91 & 6,49 & 1,15 & 6,49 & 0,18 \\
\hline Senhor do Vale & 0,06 & 0,07 & 0,40 & 1,30 & 6,36 & 1,16 & 6,36 & 0,18 \\
\hline Linear do Fogo & 0,09 & 0,16 & 0,62 & 1,39 & 6,90 & 1,15 & 6,90 & 0,17 \\
\hline Vila Guilherme & 0,56 & 1,07 & 3,83 & 1,38 & 6,86 & 1,15 & 6,86 & 0,17 \\
\hline Vila Prudente & 0,18 & 0,29 & 1,21 & 1,36 & 6,76 & 1,15 & 6,76 & 0,17 \\
\hline Cidade Toronto & 0,33 & 0,58 & 2,18 & 1,35 & 6,70 & 1,15 & 6,70 & 0,17 \\
\hline Linear Caulim & 0,05 & 0,07 & 0,32 & 1,35 & 6,68 & 1,15 & 6,68 & 0,17 \\
\hline Jardim Felicidade & 0,09 & 0,08 & 0,62 & 1,45 & 7,21 & 1,14 & 7,21 & 0,16 \\
\hline Linear Mongaguá & 0,18 & 0,34 & 1,28 & 1,43 & 7,15 & 1,14 & 7,15 & 0,16 \\
\hline Nabuco & 0,09 & 0,08 & 0,66 & 1,42 & 7,05 & 1,14 & 7,05 & 0,16 \\
\hline
\end{tabular}


Anexo B. Continuação...

\begin{tabular}{|c|c|c|c|c|c|c|c|c|}
\hline Parques & $\begin{array}{c}\mathbf{R} \\
\left(x 10^{17} \frac{\mathrm{seJ}}{\mathrm{ano}}\right)\end{array}$ & $\begin{array}{c}\mathbf{N} \\
\left(x 10^{13} \frac{\mathrm{seJ}}{\mathrm{ano}}\right)\end{array}$ & $\begin{array}{c}\mathbf{F} \\
\left(x 10^{17} \frac{\mathrm{seJ}}{\mathrm{ano}}\right)\end{array}$ & $\left(\frac{E m(Y) \$}{m^{2}}\right)$ & EIR & EYR & ELR & ESI \\
\hline Casa Modernista & 0,04 & 0,04 & 0,28 & 1,46 & 7,33 & 1,14 & 7,33 & 0,15 \\
\hline Chácara das Flores & 0,12 & 0,15 & 1,03 & 1,62 & 8,22 & 1,12 & 8,22 & 0,14 \\
\hline Consciência Negra & 0,39 & 1,02 & 3,18 & 1,61 & 8,21 & 1,12 & 8,21 & 0,14 \\
\hline Linear Aricanduva & 0,36 & 1,07 & 2,86 & 1,58 & 8,05 & 1,12 & 8,06 & 0,14 \\
\hline Cordeiro & 0,10 & 0,16 & 0,88 & 1,69 & 8,64 & 1,12 & 8,64 & 0,13 \\
\hline Colina de São Francisco & 0,14 & 0,20 & 1,23 & 1,65 & 8,62 & 1,12 & 8,63 & 0,13 \\
\hline Eucaliptos & 0,05 & 0,04 & 0,39 & 1,68 & 8,52 & 1,12 & 8,52 & 0,13 \\
\hline Luz & 0,33 & 0,66 & 2,79 & 1,62 & 8,46 & 1,12 & 8,46 & 0,13 \\
\hline Vila dos Remédios & 0,32 & 0,88 & 2,95 & 1,75 & 9,27 & 1,11 & 9,27 & 0,12 \\
\hline Faria Lima & 0,12 & 0,21 & 1,22 & 1,96 & 10,15 & 1,10 & 10,16 & 0,11 \\
\hline Buenos Aires & 0,07 & 0,07 & 0,76 & 1,94 & 11,21 & 1,09 & 11,21 & 0,10 \\
\hline Rodrigo Gásperi & 0,12 & 0,34 & 1,27 & 2,10 & 11,01 & 1,09 & 11,01 & 0,10 \\
\hline Lions Club - Tucuruvi & 0,07 & 0,11 & 0,77 & 2,09 & 10,89 & 1,09 & 10,89 & 0,10 \\
\hline Benemérito Brás & 0,06 & 0,14 & 0,81 & 2,32 & 12,52 & 1,08 & 12,52 & 0,09 \\
\hline Raul Seixas & 0,10 & 0,23 & 1,19 & 2,29 & 12,07 & 1,08 & 12,07 & 0,09 \\
\hline M Boi Mirim & 0,06 & 0,07 & 0,66 & 2,21 & 11,56 & 1,09 & 11,56 & 0,09 \\
\hline São José & 0,23 & 1,07 & 3,08 & 2,47 & 13,22 & 1,08 & 13,22 & 0,08 \\
\hline Santa Amélia & 0,10 & 0,32 & 1,29 & 2,41 & 12,82 & 1,08 & 12,83 & 0,08 \\
\hline Linear Parelheiros & 0,05 & 0,17 & 0,61 & 2,41 & 12,77 & 1,08 & 12,78 & 0,08 \\
\hline Jacinto Alberto & 0,12 & 0,56 & 1,90 & 2,90 & 15,73 & 1,06 & 15,73 & 0,07 \\
\hline Ermelino Matarazzo & 0,02 & 0,05 & 0,24 & 2,90 & 15,65 & 1,06 & 15,65 & 0,07 \\
\hline Aclimação & 0,32 & 1,09 & 4,65 & 2,61 & 14,33 & 1,07 & 14,33 & 0,07 \\
\hline Linear Guaratiba & 0,09 & 0,45 & 1,40 & 3,01 & 16,42 & 1,06 & 16,43 & 0,06 \\
\hline Independência & 0,48 & 0,22 & 10,83 & 4,12 & 22,40 & 1,04 & 22,41 & 0,05 \\
\hline Chico Mendes & 0,02 & 0,19 & 0,95 & 0,93 & 39,51 & 1,03 & 39,55 & 0,03 \\
\hline Praia do Sol & 0,05 & 0,81 & 2,51 & 8,40 & 49,67 & 1,02 & 49,75 & 0,02 \\
\hline Vila Silvia & 0,01 & 0,17 & 0,60 & 8,21 & 48,10 & 1,02 & 48,16 & 0,02 \\
\hline Zilda Natel & 0,01 & 0,11 & 0,56 & 14,08 & 86,18 & 1,01 & 86,32 & 0,01 \\
\hline
\end{tabular}

